\title{
Entre el pragmatismo y el consenso: los vínculos del gobierno cubano y la última dictadura argentina (1976-1983)
}

\author{
Between Pragmatism and Consensus: The \\ Ties of the Cuban Government and the \\ Last Argentine Dictatorship (1976-1983)
}

\author{
Alberto Consuegra Sanfiel* \\ (D) https://orcid.org/0000-0002-4795-3525 \\ Grupo de Estudios sobre Centroamérica \\ Instituto de Estudios de América Latina y el Caribe (IEALC) \\ Universidad de Buenos Aires, Argentina \\ albertoconsuegra@yahoo.es
}

Resumen: El presente artículo tiene como objetivo explorar el desarrollo de las relaciones diplomáticas entre el gobierno revolucionario cubano y el gobierno de facto argentino entre 1976 y 1983. La mayoría de los trabajos que han abordado las relaciones exteriores de la revolución cubana durante el periodo de la guerra fría han centrado su atención en el análisis del diferendo Estados Unidos-Cuba, o en los vínculos Cuba-URSS y Cuba-África, circunscribiendo

* Doctor en Historia por la Universidad de Buenos Aires, Argentina. Becario posdoctoral en el Instituto de Investigaciones en Humanidades y Ciencias Sociales (IIHCS), Universidad Nacional de La Plata-Conicet, La Plata; miembro/investigador del Grupo de Estudios sobre Centroamérica, Instituto de Estudios de América Latina y el Caribe (IEALC), Universidad de Buenos Aires, Argentina. Líneas de investigación: historia latinoamericana contemporánea, guerra fría, historia de Cuba y el Caribe.

Cómo citAR: Consuegra Sanfiel, A. (2021). Entre el pragmatismo y el consenso: los vínculos del gobierno cubano y la última dictadura argentina (1976-1983). Secuencia (111), e1950. DoI: https://doi.org/10.18234/ secuencia.v0i111.1950 
las relaciones exteriores del país caribeño a la confrontación "Este-Oeste". Precisamente, el estudio exploratorio que aquí se presenta permite refrendar el carácter pragmático de la política exterior cubana a partir de 1970, el complejo entramado de vínculos y relaciones que se desarrollaron en el marco de la guerra fría en la región latinoamericana, así como la importancia de las relaciones con Cuba para la dictadura argentina.

Palabras clave: Cuba; Argentina; relaciones diplomáticas; dictadura; guerra fría.

Abstract: This article aims to explore the development of diplomatic relations between the cuban revolutionary government and the argentine de facto government between 1976 and 1983. Most of the works that have addressed the foreign relations of the Cuban revolution during the period of the cold war have focused their attention on the analysis of the United States-Cuba dispute, or on the Cuba-USSR and Cuba-Africa ties, limiting the foreign relations of the caribbean country to the "East-West" confrontation. Precisely, the exploratory study presented here allows us to endorse the pragmatic nature of cuban foreign policy since 1970, the complex network of ties and relationships that developed in the framework of the cold war in the Latin American region, as well as the importance of relations with Cuba for the argentine dictatorship.

Key words: Cuba; Argentina; diplomatic relations; dictatorship; cold war.

Recibido: 31 de enero de 2021 Aceptado: 2 de agosto de 2021

Publicado: 25 de octubre de 2021

\title{
INTRODUCCIÓN
}

\begin{abstract}
Cada 24 de marzo en Argentina se ha hecho costumbre ver, en cada marcha y de la mano de miembros del Movimiento Argentino de Solidaridad con Cuba, pancartas con las caras de los cubanos Jesús Cejas Arias y Crescencio Galañena Hernández. Sus nombres, como los de tantos uruguayos, brasileños, paraguayos, pero sobre todo argentinos, forman parte de la inter-
\end{abstract}


minable lista de torturados y desaparecidos que provocó la última dictadura militar en Argentina. Y es que entre 1976 y 1978 se desarrollaron en el país conosureño operativos militares violentos contra la embajada cubana en Buenos Aires, los cuales involucraron a 22 personas -cinco cubanos y 17 argentinos y argentinas-, quienes fueron secuestradas, torturadas y desaparecidas, actos que a juzgar por la exembajadora argentina en Cuba, Juliana Marino, "fueron la respuesta a la actitud de solidaridad que tuvo la embajada cubana para con los perseguidos políticos argentinos en aquella etapa" (Prieto-Solís Cubas, 2016).

A grandes rasgos, las acciones formaron parte de los actos terroristas que llevó a cabo la Coordinación de Organizaciones Revolucionarias Unidas $(\mathrm{CORU})^{1}$ contra las representaciones diplomáticas, comerciales y el personal del país caribeño alrededor del mundo, en el marco de la llamada "guerra por los caminos del mundo", durante las décadas de 1970 y 1980. Las mismas estuvieron enmarcadas en la Operación Gillette y contaron con la anuencia tanto de Washington como de algunos gobiernos en América Latina (Méndez Méndez, 2011). Tal fue la colaboración entre las instituciones militares y las organizaciones argentinas de derecha que, por ejemplo, en el centro de la ciudad de Buenos Aires y a plena luz del día, el 13 de agosto de 1975 un comando de la organización Acción Cubana -grupo terrorista integrante activo de la CORU - atentó contra la vida del embajador cubano en Argentina, Emilio Aragonés Navarro, abriendo fuego contra su automóvil en marcha, lo que provocó heridas al personal de seguridad del diplomático.

Si bien el periodismo nacional e internacional destacó rápidamente el "incidente", el cual fue presentado como un hecho más de las tantas acciones violentas que venían sucediendo en el territorio austral, el 22 de agosto la prensa publicó un comunicado el cual, además de señalar a los autores, tenía como trasfondo reducir las responsabilidades del gobierno argentino. La organización signataria del comunicado -el Consejo Revolucionario Anticomunista Latinoamericano (CRAL) - reconocía la autoría del hecho contra el embajador cubano en suelo argentino, además de que dejó claro el carácter anticomunista y terrorista del mismo al expresar:

${ }^{1}$ La Coordinación de Organizaciones Revolucionarias Unidas (CORU) fue una organización terrorista fundada en República Dominicana el 15 de junio de 1976 por Orlando Boch, terrorista cubano exiliado en Estados Unidos. 
Los hombres revolucionarios de América, preocupados por el avance del comunismo en nuestros pueblos, hemos constituido un frente solidario, el cual se conocerá como CRAL. Nuestra meta es internacionalizar la guerra a niveles continentales, aplicando justicia a los traidores de la libertad de Cuba. Nuestras aspiraciones son las mismas que animaron a nuestros próceres: libertad y justicia. Por tanto, hacemos un llamado a todos los hombres anticomunistas de América para que se apresten a la lucha en cualquier parte donde radiquen. Nuestra primera acción fue el atentado contra el Embajador de Cuba comunista en Argentina, Emilio Aragonés. Las ráfagas de ametralladoras y la metralla harán comprender a los servidores castristas que no existen fronteras que detengan la acción de los hombres que aman la libertad. Por ser Cuba el único país de América donde impera un régimen comunista declarado y por ser este país el que más ha sufrido bajo este infrahumano sistema, hubimos de acordar que fuera Acción Cubana y su dirigente Orlando Bosch, quienes dirigieran esta primera acción dentro de la nueva y prometedora etapa que comienza (Méndez Méndez, 2006, p. 77).

Teniendo en cuenta estos antecedentes, además del ferviente posicionamiento anticomunista de la Junta Militar argentina, la cual gobernó el país de 1976 a 1983, cuyo objetivo confeso fue la lucha contra la "subversión de izquierda”, sería imposible imaginar que el gobierno de La Habana mantuviera, después del 24 de marzo de 1976 y hasta 1983, estrechas relaciones en el ámbito diplomático con el gobierno de facto que presidió en Argentina durante ese periodo. Sin embargo, la desclasificación de algunos documentos diplomáticos por parte de la cancillería argentina, la revisión de publicaciones periódicas cubanas y extranjeras de la época, así como el acceso a fuentes secundarias de carácter periodístico y/o documental que han abordado el tema -los cuales recogen importantes testimonios-, indican que el gobierno cubano mantuvo cordial relación con el gobierno militar de Argentina, a diferencia del posicionamiento que mantuvo para regímenes de igual tipo que se desarrollaron en la región, por ejemplo, con Paraguay, Chile y Uruguay.

Precisamente, el objetivo de este trabajo es hacer una exploración del tema en cuestión, poniendo a debate aquellos factores, tanto internos como externos, que modelaron y/o influyeron en las relaciones entre Cuba y Argentina durante el periodo 1976-1983. Es importante destacar que el presente artículo no busca abarcar todos los aspectos de las relaciones entre ambos países, sino sólo analizar cómo se desarrollaron las relaciones políticas y 
diplomáticas entre ambos gobiernos, señalando aquellos elementos indispensables que permitirían una mejor comprensión del fenómeno en su conjunto, así como los intereses y tendencias que motivaron y caracterizaron las relaciones entre ambas naciones.

Asimismo, si bien el estudio propuesto demuestra que el golpe de Estado que se dio en Argentina el 24 de marzo de 1976 no constituyó una ruptura entre los vínculos interestatales entre dichos países, se reconoce el lugar que ocupó Cuba como destino y/o lugar de tránsito para muchos exiliados argentinos, así como los vínculos directos y el apoyo brindado por el gobierno cubano a las diferentes organizaciones de izquierda argentina, lo cual refuerza la importancia del tema como fenómeno que particulariza el impacto y el desarrollo de la guerra fría en Latinoamérica.

\section{CUBA Y ARGENTINA: "NUEVA” POLÍTICA EXTERIOR Y OTRA VEZ NUEVOS “AMIGOS” (1973-1976)}

Investigar y escribir sobre la revolución cubana -cualquiera de sus aspectos, particularmente sobre las relaciones exteriores y desde Cuba- no ha sido un proceso académico fácil y mucho menos homogéneo. En sentido general, las investigaciones y los análisis hechos presentan abordajes limitados -producto de la influencia de los cambios ideológicos que trajo consigo el triunfo revolucionario de 1959-, lo que ha condicionado, hasta nuestros días, la producción intelectual y las perspectivas desde las cuales se debe abordar la historia cubana.

Signada por la irrupción y apropiación de preceptos teóricos provenientes del marxismo ortodoxo, en unión al propio desarrollo de los hechos, no fue sino hasta finales de los años ochenta, con el advenimiento del "proceso de rectificación de errores y tendencias negativas" ${ }^{2}$ la total desconexión de Cuba de la órbita de la influencia de la URSS, además de las necesidades propias que el análisis histórico impuso con el paso del tiempo, que salieron a la luz publicaciones que abordaron las relaciones exteriores del gobierno

2 El "proceso de rectificación de errores y tendencias negativas", que comenzó por la economía, se hizo extensivo a toda la sociedad en su conjunto en un esfuerzo por buscar un camino propio, autóctono y eficiente para el socialismo cubano. Tuvo su inicio en 1984, con el llamado a la celebración del Tercer Congreso del Partido Comunista de Cuba, el cual se celebró en 1986. 
revolucionario cubano con América Latina durante las décadas de 1960 y 1970. Esto hizo que se dejaran de lado temas como el movimiento obrero, las luchas estudiantiles, las relaciones Estados Unidos-Cuba y los estudios económicos y políticos, contenidos que habían ocupado el centro de la producción historiográfica durante casi tres décadas.

Así, lentamente, aparecieron trabajos monográficos y artículos académicos que, en líneas generales, delinearon la política exterior cubana, tanto con América Latina como con el resto del mundo, enfatizando, sobre todo para el caso de la región latinoamericana y caribeña, en la ayuda de Cuba a los movimientos armados, así como en la impronta del proceso revolucionario como agente transformador de las relaciones interamericanas después de 1959 (Domínguez, 1997; Rodríguez, 1983; Suárez Salazar, 1986, 1997). La mayoría de sus autores toman el ascenso del gobierno de la Unidad Popular en Chile como un punto de inflexión en las relaciones cubano-latinoamericanas, reconociendo también, a partir del golpe perpetrado por Augusto Pinochet tres años más tarde, el inicio en Cuba de una fuerte campaña de denuncias contra los procesos dictatoriales que se establecieron en el Cono Sur durante las décadas de 1970 y 1980.

Es importante destacar que dicha periodización coincide con la implementación por parte de Cuba de cambios significativos en su política exterior. Después de 1959, Cuba apoyó abiertamente a los movimientos guerrilleros en la región (Bush y Suárez, 2009; Kruijt, 2019; Liberman, 2017; Prieto, 2017; Ratliff, 1976), posición que cambió a finales de la década de 1960 al desplegar una política exterior que se centró en superar el aislamiento económico y diplomático que padecía el país. Además de la importancia de establecer acuerdos económicos, la dirigencia revolucionaria buscó lograr la legitimidad del proceso transformador a través de la implementación de una política exterior pragmática con fuerte anclaje en la diplomacia, la cual estuvo dirigida a conciliar los intereses nacionales sin abandonar la orientación ideológica (Alzugaray, 2009; Castañeda, 1995; Kruijt, 2019; Marchesi, 2017).

Fue así que, durante los años setenta, La Habana estableció relaciones diplomáticas con Perú, Ecuador, Panamá, Venezuela, Colombia, entre otros, y por supuesto, con Argentina (Kruijt, 2019, p. 286). Exactamente en 1973, con la llegada del gobierno justicialista de Héctor J. Cámpora, ambos países reanudaron las relaciones bilaterales después de más de once años de ruptura, las cuales se materializaron con el asentamiento mutuo de sendas misiones diplomáticas, visitas oficiales y, sobre todo, el intercambio mercan- 
til. Durante este periodo, uno de los acuerdos en materia económica de mayor significación fue el otorgamiento de un préstamo del Banco Central de la República Argentina (BCRA) al país caribeño por 1278000 dólares (Frediani, 2019). Propuesto por el entonces ministro de Economía, José B. Gelbard, el acuerdo financiero consistía en la transferencia de dicho monto a Cuba con el propósito de financiar la venta de productos argentinos tales como maquinaria agrícola, tractores, camiones pesados, y varios modelos de autos, los cuales se compraban con el propósito de aumentar las flotas de taxis de las grandes ciudades del país caribeño (Frediani, 2019).

Además de las posibles ventajas económicas que se abrieron para ambos países, lo cierto es que, para Cuba, el restablecimiento de las relaciones con Argentina significó un gran soporte para el avance de la diplomacia en Latinoamérica, en medio de un contexto cada vez más adverso y abiertamente “anticomunista”. Tal como había sucedido en Paraguay (1954), Brasil (1964) y Bolivia (1971), en 1973 se suscitaron sendos golpes de Estado en Uruguay y Chile, lo que convirtió a la región en una cofradía de regímenes militares que, desde el primer momento, se opusieron a Cuba. Asimismo, el nombramiento de Emilio Aragonés Navarro como embajador de Cuba en Argentina es otro de los elementos que permite calibrar la importancia y el significado otorgado por Cuba al restablecimiento y la consolidación de las relaciones bilaterales con el país austral. Aragonés Navarro, quien fue el jefe de la misión cubana en Buenos aires entre 1973 y 1983, había sido miembro de la dirección política de la revolución, integrante de la guerrilla que había dirigido el Che en el Congo, y miembro fundador del "Movimiento 26 de julio", además de haber ocupado disímiles cargos políticos y de representación, medulares todos, desde 1959 (Méndez Méndez, 2006, p. 76). Y es que, además de priorizar las "relaciones con países democráticos capitalistas bajo el principio de pluralismo ideológico" (Castro, 1985, p. 97), el pragmatismo en la nueva etapa de la política exterior cubana consistió también en seleccionar minuciosamente a reconocidas personalidades de la política revolucionaria cubana que, además de ser hombres y mujeres cercanos a Fidel Castro (Kruijt, 2019, p. 286), proveyeran de nuevos bríos y confianza los vínculos de Cuba con Latinoamérica.

Convencidos de la necesidad de seguir de cerca todo cuanto acontecía en Argentina, donde existía una embajada que facilitaba el trabajo de recopilación de información y contacto con las organizaciones de izquierda de la región -chilenas, uruguayas y argentinas-, antes del 24 de marzo de 1976, fecha en que se perpetró el golpe de Estado contra la presidencia de María 
Estela Martínez de Perón, el gobierno cubano siguió de cerca todo lo que acontecía en el país en el ámbito político y social. La revisión de las páginas del periódico cubano Granma, órgano oficial del Partido Comunista de Cuba, dan cuenta del monitoreo que, a través de la noticia, ${ }^{3}$ se venía haciendo de la situación, mientras se reconocía un progresivo deterioro de estabilidad del país, sobre todo en lo referente al aumento de la represión contra los militantes y miembros de organizaciones de izquierda. Sin embargo, a diferencia de lo que se informaba sobre los arrestos, desapariciones y asesinatos llevados a cabo por el sector castrense en Uruguay, Chile y/o Paraguay contra los militantes de izquierda, periodistas, dirigentes sindicales y estudiantiles, las noticias de igual porte que llegaban desde Buenos Aires eran presentadas con menos vehemencia que las de los países vecinos, circunscribiéndose las mismas a simples descripciones.

Tan es así que, por ejemplo el 8 de enero de 1976, en referencia a un viaje que haría Alfredo Stroessner a Uruguay, el diario dio a conocer la noticia a través de una nota titulada: "Encuentro de gorilas en Uruguay", expresando lo siguiente:

El dictador de Paraguay, general Alfredo Stroessner, permanecerá cinco días en Uruguay, durante la visita oficial que realizará en febrero, revelaron fuentes oficiales. Stroessner arribará a Montevideo el 3 de febrero y permanecerá hasta el día 7, con la finalidad de retribuir la visita que en mayo último efectuó a Paraguay el representante del régimen uruguayo, el no menos sanguinario Juan María Bordaberry, informan las fuentes que ambos gorilas suscribirán algunos convenios. ${ }^{4}$

Sin embargo, en la misma sesión se informó acerca de la explosión de unas bombas lanzapanfletos en la ciudad de Córdoba, Argentina, donde se abogaba por la libertad del dirigente montonero Roberto Quieto, quien ya se encontraba para esa fecha desaparecido, y se hacía de manera diferente,

${ }^{3}$ La principal fuente de noticias de la que se nutría Cuba sobre las realidades latinoamericanas, y en particular de Argentina, era la agencia de información Prensa Latina. Una vez que se restablecieron las relaciones diplomáticas con el país, en 1973, y a su vez se perpetró el golpe de Estado a Allende en Chile, la corresponsalía en Buenos Aires pasó a ser fundamental para el flujo informativo desde el sur de América Latina hacia el mundo y, en particular, hacia Cuba.

${ }^{4}$ Editorial, "Encuentro de gorilas en Uruguay", Granma, La Habana, 8 de enero de 1976, p. 7. 
circunscribiéndose a brindar la información sin hacer juicios de valor, como sí sucedió con casi todos los arrestos arbitrarios, asesinatos y desapariciones que se informaban de militantes chilenos, paraguayos o charrúas. La nota decía: "Tres bombas lanzapanfletos con volantes en cuyo texto se exige la libertad del dirigente montonero Roberto Quieto, estallaron ayer en Córdoba en diferentes lugares y a distintas horas. Quieto es uno de los principales dirigentes de la organización guerrillera y fue detenido o secuestrado el 29 de diciembre último." ${ }^{5}$

Mientras Granma denunciaba abiertamente la represión que llevaban a cabo los militares en la región, y apelaba a la palabra "secuestro" para referirse a la situación de los miles de hombres y mujeres que fueron víctimas de los operativos de los cuerpos de seguridad en el Cono Sur a lo largo del periodo 1976-1983, se puede apreciar que la forma de informar sobre lo que sucedía en la Argentina fue cauta, pudiéndose afirmar que la actitud del gobierno de La Habana fue diferente, al menos desde el punto de vista oficial.

Desde esa fecha, también se podía vislumbrar la política de "doble canal” que aplicaría Cuba para con el país austral pues, si bien nunca rompió relaciones con las Juntas Militares, muchos argentinos y argentinas se exiliaron en el país, además de que apoyó a organizaciones guerrilleras como Montoneros y Ejército Revolucionario del Pueblo (ERP). Antes del golpe, por ejemplo, el Partido Comunista de Cuba se solidarizó con el Partido Comunista Argentino (PCA) por la aparición con vida de Alberto Cafaratti, miembro del Comité Central del partido, ${ }^{6}$ quien había sido "secuestrado o detenido"; ${ }^{7}$ hizo pública la detención del escritor Gregorio Selser en febrero de 1976, cuando regresaba de un viaje procedente de Perú, ${ }^{8}$ además de hacer pública la detención en suelo argentino del dirigente chileno del Movimiento de Izquierda Revolucionaria (MIR), Edgardo Enríquez, ${ }^{9}$ entre otros casos.

${ }^{5}$ Editorial, "Estallan bombas con volantes en Córdoba", Granma, La Habana, 8 de enero de 1976, p. 7.

${ }^{6}$ Editorial, "Exige el PCA la aparición de Alberto Cafaratti, miembro de su Comité Central”, Granma, La Habana, 16 de enero de 1976, p. 6.

7 "Secuestrado o detenido" fue la terminología que usó Granma para referirse en las noticias para los casos de Argentina, mientras que, para el resto de la región, directamente se va a referir como "secuestrado".

${ }^{8}$ PL, "Arrestado en Buenos Aires el periodista argentino Gregorio Selser; ignóranse las razones de su detención", Granma, La Habana, 11 de febrero de 1976, p. 7.

9 PL, "Denuncian que fue detenido en Argentina, Edgardo Enríquez, dirigente del MIR de Chile”, Granma, La Habana, 30 de abril de 1976, p. 7. 


\section{EL GOLPE DE ESTADO: PUNTO DE NO INFLEXIÓN EN LOS VÍNCULOS DIPLOMÁTICOS ENTRE CUBA Y ARGENTINA}

Como se mencionó anteriormente, el golpe de Estado del 24 de marzo de 1976 no constituyó un quiebre en las relaciones entre Cuba y Argentina, las cuales se mantuvieron a igual ritmo, incluso, llegando a ser muy estrechas en algunos momentos. A través del análisis de la comunicación entre la embajada argentina en La Habana y la cancillería, se pueden detectar algunos ejes sobre los que descansaron las relaciones entre ambos países, el grado de colaboración e intercambio en la arena internacional, los puntos sobre los que la misión diplomática se enfocó, además de que permite describir la dinámica de un fenómeno, el de las relaciones de dos gobiernos con ideologías opuestas que, en el marco de la guerra fría, socaba la interpretación clásica del periodo, que no ha sido otra que afirmar que la región se encolumnó detrás de la política exterior estadunidense o soviética (Bethell y Roxborough, 2005; Marchesi, 2017, pp. 187-202; Pettinà, 2018).

De acuerdo con la documentación consultada en el Archivo Histórico de la Cancillería argentina, se puede afirmar que hubo un constante flujo de información por parte de las autoridades diplomáticas asentadas en la isla hacia la cancillería argentina, el cual se encaminó en tres direcciones: el propósito manifiesto de las autoridades cubanas a estrechar vínculos económicos con Argentina, el apoyo recibido por ambos gobiernos en cuanto a candidaturas y elecciones que se hicieron al interior de organismo multilaterales, así como el papel que cumplió el país austral, a través de su sede diplomática en La Habana, en la transmisión de información acerca de los movimientos, alcances y limitaciones de Cuba en la lucha por la liberación de los pueblos de África, puntualmente de Angola y de Etiopía, ${ }^{10}$ además de su protagonismo en la crisis migratoria que vivió la isla en 1980.

A casi un año de haberse perpetrado el golpe, Argentina comenzó a hacer gestiones con el fin de que el gobierno cubano apoyara al régimen militar argentino para ser reelegido como miembro en la subcomisión del Consejo Económico y Social de las Naciones Unidas (ECOSOC), organismo encargado, contradictoriamente, de elevar a la Comisión de Derechos Humanos de las

${ }^{10}$ Este aspecto, por un problema de extensión del artículo, no será desarrollado, dándole prioridad a otros aspectos. 
Naciones Unidas los casos de los países que cometían violaciones. ${ }^{11}$ Si bien las conversaciones al respecto duraron unos meses, de la misma comunicación se puede extraer cómo la búsqueda del respaldo del país caribeño estuvo condicionada por el voto positivo que le daría Argentina a la candidatura de Cuba para integrar el Consejo Ejecutivo de la Organización Mundial de la Salud (oMs), en mayo de ese mismo año. ${ }^{12}$ No obstante, si bien en agosto la cancillería precisó lo anterior a las autoridades cubanas a través de su representante diplomático en la isla, desde abril funcionarios argentinos de la embajada habían comenzado a tener encuentros con el Ministerio de Relaciones Exteriores de Cuba (Minrex) a fin de conseguir el apoyo a cambio del voto argentino para la candidatura cubana en la oms. ${ }^{13}$

Sin embargo, estas no fueron las únicas gestiones que se hicieron entre ambos gobiernos con el fin de recibir apoyos mutuos en la arena internacional. Si se hace un análisis de las comunicaciones diplomáticas de la embajada argentina en La Habana que se pueden consultar, 1979 fue uno de los años donde más apoyo diplomático requirió Cuba por parte del gobierno militar argentino. Según un cable secreto enviado desde La Habana hacia Buenos Aires, la cancillería cubana le solicitó al gobierno argentino aval a su candidatura para integrar la Comisión de Derecho Mercantil Internacional, presentación y votación que se haría en el trigésimo cuarto periodo de sesiones de la Asamblea General de las Naciones Unidas. ${ }^{14}$

Asimismo, el fuerte protagonismo que tenía Argentina al interior del Grupo Latinoamericano (GRULA) como máximo representante de la región ante la Comunidad Europea ( $\mathrm{CE}$ ), motivó a que las autoridades cubanas contactaran a la misión permanente argentina frente a la organización para solicitarles, una vez más, apoyo para su entrada al grupo, notificación que se

${ }^{11}$ Candidatura Argentina en Ecosoc, 11 de agosto de 1977. Cable secreto de la cancillería a la embajada argentina a La Habana, núm. 108. Archivo del Ministerio de Relaciones Exteriores y Culto (en adelante Amrec), Argentina.

12 Candidatura Argentina en Ecosoc, 11 de agosto de 1977. Cable secreto de la cancillería a la embajada argentina a La Habana, núm. 108. Amrec, Argentina.

13 Candidatura Argentina (ECOSOC) y Cuba (OMs), 20 de abril de 1977. Cable secreto de la cancillería a la Embajada de Argentina en La Habana, núm. 53; Informa Minrex Cuba. Ecosoc por oms, 30 de abril de 1977. Cable secreto de la Embajada de Argentina en La Habana a la cancillería, núm. 111. AMrec, Argentina.

14 Solicitud de apoyo de la cancillería local a candidatura cubana. 31 de enero de 1979. Cable secreto de la Embajada de Argentina en La Habana a la cancillería, núm. 40. AMREC, Argentina. 
envió a la cancillería a través de un cable secreto el 21 de mayo de $1979 .{ }^{15} \mathrm{Al}$ respecto, es importante destacar que el grupo político-regional al cual Cuba pretendía integrarse -GRULA- tenía buena predisposición con el país caribeño pues, según otra comunicación que enviase la embajada argentina en La Habana a Buenos Aires, transmitiendo la necesidad de saber la posición oficial del gobierno argentino ante la posibilidad de que Cuba fuera la sede de la Conferencia de las Naciones Unidas sobre Comercio y Desarrollo (UNCTAD), la cual se celebraría entre 1982 y 1983, afirmaba que el grupo le había otorgado el aval. ${ }^{16}$

Al respecto, el cable daba cuenta de lo siguiente:

[...] POSICIÓN EXTRAoficial ARgENTINA Y EN GENERAL GRULA HABRíA SIDO FAVORABLE SEDE CUBA EN RECIENTES REUNIONES ARUSHA, TANZANIA. DADO QUE CRITERIO A ELEVARSE ASAMBLEA GENERAL SERÍA ADOPTADO EN REUNIÓN MANILA, QUE COMIENZA PRÓXIMO TRES DE MAYO, O BIEN EN SUBSECUENTE CONFERENCIA JUNTA COMERCIO Y DESARROLLO, CANCILLERÍA LOCAL RUEGA CONTAR CON POSICIÓN OFICIAL ARGENTINA ANTES CITADA FECHA. ESTIMARÉ URGENTE RESPUETA. ${ }^{17}$

¿A qué se debía el ímpetu del gobierno revolucionario y su afán por tener una presencia activa en los organismos internacionales?, ¿por qué la Junta Militar argentina apoyaba a Cuba? Son preguntas que tal vez no puedan ser respondidas en su totalidad en un trabajo como este, el cual tiene un carácter exploratorio más; sin embargo, algunos elementos podrían acercarnos en un análisis a priori. Uno de los elementos a tener en cuenta es la estabilidad económica e institucional que transitó el proceso revolucionario cubano desde 1975, el cual se reflejó claramente en la política exterior. Si bien desde 1959 Cuba tuvo una actitud fuerte y activa frente a la región (Buch y Suárez, 2009), la celebración del Primer Congreso del Partido Comunista de

15 Presidente Grula distribuyó agenda. Tema Cuba ingreso, 21 de mayo de 1979. Cable secreto de la Misión Permanente ante la Comunidad Europea, núm. 341. AMREC, Argentina.

${ }_{16}$ Referido a posibilidad de que Cuba sea sede de reunión UNCTAD 1983/1984, 20 de abril de 1979. Cable secreto de la Embajada de Argentina en La Habana a la cancillería, núm. 172. AMrec, Argentina.

17 Referido a posibilidad de que Cuba sea sede de reunión UNCTAD 1983/1984, 20 de abril de 1979. Cable secreto de la Embajada de Argentina en La Habana a la cancillería, núm. 172. AMrec, Argentina. 
Cuba y la discusión y aprobación de la Constitución de 1976, junto a la estabilidad económica que le ofreció la colaboración de la Unión de Repúblicas Socialistas Soviéticas (URSS), además de favorables precios en el mercado internacional azucarero, allanaron el camino para que se fortificara la política exterior. Así, en ese mismo año, por ejemplo, se celebró el I Festival del Nuevo Cine Latinoamericano y La Habana fue sede de la VI Cumbre del Movimiento de Países No Alineados (MNOAL) (Silva, 2005, pp. 258-321).

A nivel regional la correlación de fuerzas también había cambiado. Respecto a Estados Unidos, la llegada del representante demócrata Jimmy Carter a la presidencia estadunidense permitió un acercamiento entre los dos países, fenómeno que se tradujo, sobre todo, en la apertura de diversas oficinas en Washington y La Habana, situación que fue aprovechada por ambos gobiernos para cambiar la rudeza de sus posiciones ante los ojos del mundo. Asimismo, el triunfo de la revolución sandinista en Nicaragua y la de Granada, además de la incorporación de Cuba en la lucha por la independencia de Angola y la participación militar en Etiopía, se convirtieron en elementos de peso que coadyuvaron a reforzar las miradas externas, pero también las internas. No hay duda de que la isla caribeña se consolidó como el referente de las izquierdas latinoamericanas y mundiales.

Por su parte, para la Junta Militar argentina, a la altura de 1978, cualquier acercamiento con Cuba contribuiría a mejorar la imagen de un gobierno de facto que claramente asesinaba, torturaba y desaparecía a la oposición política. Como parte de contrarrestar la famosa "campaña antiargentina", no hay dudas de que la cercanía y el apoyo del gobierno militar argentino para el de La Habana tenía un único objetivo: limpiar su imagen ante el mundo, en particular con la izquierda europea y latinoamericana. Y es que Cuba -referente del Tercer Mundo y de la izquierda mundial- se convirtió en un recurso de legitimidad esencial que, sobre todo después de 1978, le sirvió a las Fuerzas Armadas argentinas para reformular la imagen del sistema político desde un aparente "consenso", pero con las Fuerzas Armadas en el poder (Canelo, 2001; Lvovich, 2010).

De igual forma, existen dos elementos que merecen especial atención con el fin de poder entender mejor las relaciones Cuba-Argentina durante el periodo de estudio, así como determinar cuál fue su impacto en las mismas: la presencia de la cúpula de la organización Montoneros y el apoyo militar cubano a la Contraofensiva (1978-1980) (Argento, 2013), así como la recepción por parte 
del gobierno cubano del informe que hizo la Comisión Interamericana de Derechos Humanos (CIDH) en 1979, donde se explicitó públicamente que

A la luz de los antecedentes y consideraciones expuestos en el presente informe, la Comisión ha llegado a la conclusión de que, por acción u omisión de las autoridades públicas y sus agentes, en la República Argentina se cometieron durante el periodo a que se contrae este informe -1975 a 1979- numerosas y graves violaciones de fundamentales derechos humanos reconocidos en la Declaración Americana de los Derechos y Deberes del Hombre (CIDH, 1979).

No obstante, pareciera que no entorpeció la cordialidad que venían manteniendo ambos gobiernos. La participación de la delegación argentina a la VI Cumbre del Movimiento de Países No Alineados fue uno de los hechos que mejor lo representó. Cumpliendo con la invitación formal que le hiciera Cuba, además de pertenecer a la organización, la Junta Militar envió a sus representantes a la celebración de la VI Cumbre, la cual se celebró en Cuba entre los días 26 de agosto y 7 de septiembre de 1979. Paradójicamente, en un encuentro donde las denuncias y la lucha contra las prácticas "fascistas e imperialistas", en pleno auge de la guerra fría, atravesaban el MNOAL, asistieron en nombre del gobierno argentino de facto el comodoro Carlos Roberto Francisco Cavandoli, quien era el subsecretario de Relaciones Exteriores,$^{18}$ así como Edgar Joaquín Flores Gómez y Carlos Arturo Francisco Spinosa, consejero y secretario de Primera Clase de la embajada argentina en La Habana. ${ }^{19}$

La participación argentina en la cumbre tuvo meses de preparación en medio de un contexto global adverso para la Junta Militar argentina en relación con los derechos humanos, además de que se conversó previamente con Cuba la no inclusión de temas relacionados con la situación de Argentina, asegurándose de que no se adoptaran resoluciones en su contra. Para esto, el gobierno cubano designó a Francisco García Valls, ministro del Comité Estatal de Finanzas, como representante personal del presidente Fidel Castro quien, junto al embajador cubano en Buenos Aires, Emilio Aragonés, tenían la misión de entrevistarse con Videla para entregarle personalmente la invi-

${ }^{18}$ El comodoro D. Carlos Roberto Francisco Cavandoli fue nombrado como subsecretario de Relaciones Exteriores, a través del Decreto S 56/1979 y firmado por Jorge Rafael Videla, presidente de facto de Argentina en 1979.

${ }_{19}$ Resolución 1546. Ministerio de Relaciones Exteriores y Culto, República Argentina, 19 de octubre de 1979. Reservado. AmRec, Argentina. 
tación, además de organizar con funcionarios argentinos todo lo relacionado con la participación del país austral. ${ }^{20}$

Si bien hasta el momento no existen fuentes fidedignas que confirmen la concreción del encuentro, lo cierto es que las autoridades cubanas mostraron firmes intenciones de llevar a cabo la reunión con el alto militar pues, previo a la visita de García Valls a Argentina, al no tener confirmación por parte de las autoridades argentinas sobre posibilidad de la reunión, la embajada argentina en La Habana informó a la cancillería las intenciones del gobierno cubano de que el encuentro García Valls-Videla se podía posponer para el día 28 o 29 de abril, o de lo contrario para el 11 o 12 de mayo. ${ }^{21}$ La designación del ministro cubano, según un cable argentino llegado desde La Habana, indicaba la importancia que tenía Argentina para la consolidación y expansión de relaciones bilaterales, en particular, en el ámbito económico.

Las intenciones de comerciar y consolidar las relaciones económicas con Argentina por parte de Cuba se pueden extraer de las mismas comunicaciones que enviaban las autoridades diplomáticas argentinas desde La Habana. En el mes de mayo de 1979, por ejemplo, viajó al país isleño una delegación de empresarios argentinos, ocasión que fue aprovechada por las autoridades cubanas del Ministerio de Comercio Exterior para exponer las intenciones de invitar al país al secretario de Comercio, al subsecretario de Relaciones Económicas Internacionales, representantes del banco central, así como a otros grupos de empresarios. A los pocos días, otro cable ahondó en la importancia y la relevancia de la visita de los empresarios argentinos, además de enumerar algunos temas pendientes entre ambos países como: 1) Acuerdo de cooperación económica y comercial; 2) Acuerdo sobre transporte marítimo, y 3) Acuerdo financiero; asuntos todos que estaban relacionados con un acuerdo económico que se había firmado en $1976 .^{22}$

${ }^{20}$ Relativo a viaje embajadores cubanos para presentar al presidente invitación a VI Conferencia de No Alineados, posibles temas de agenda económica bilateral, 21 de marzo de 1979. Cable secreto de la Embajada de Argentina en La Habana a la cancillería, núm. 128/28/30. AMrec, Argentina.

${ }^{21}$ Embajada de la República en Cuba, comunica confirmación viaje ministro Finanzas a Buenos Aires, fecha no confirmada. 4 de abril de 1979. Cable secreto de la Embajada de Argentina en La Habana a la cancillería, núm. 148/149. AMrec, Argentina.

${ }^{22}$ Embajada de la República en Cuba, sobre acuerdos comerciales y financieros; ministro Económico y Comercial solicita instrucciones, 22 de mayo de 1979. Cable secreto de la Embajada de Argentina en La Habana a la cancillería, núm. 202/203; Embajada de la República en 
Sin embargo, si bien la participación argentina al encuentro de los MNOAL en La Habana puede ser entendida como una muestra de cordialidad para Cuba, además de que también fue una oportunidad para atenuar la imagen negativa en el exterior a partir del informe de la CIDH, lo cierto es que la presencia de la delegación argentina también estuvo motivada por la búsqueda de mayor protagonismo al interior del grupo, el cual se creía que podía ser replicado al interior de la Organización de Naciones Unidas (ONU). En enero de 1979, el representante permanente de Argentina ante Naciones Unidas, respondiendo a una consulta que hizo la cancillería respecto a la conveniencia de la participación del gobierno a una reunión preparatoria que se celebraría en Colombo, Sri Lanka, de cara a la realización de la VI Cumbre en La Habana, recomendó la participación a la cita con el firme propósito de estrechar vínculos con países que pudieran hacer frente al peso de Cuba, ya que el país caribeño ostentaría la presidencia pro tempore del MNOAL en el próximo mandato. ${ }^{23}$

Además de indicar que "había que proceder con cautela, coordinando posiciones con países moderados que comparten igual posición”, ${ }^{24}$ también explicitaba el deseo que le habían transmitido algunos representantes de gobiernos de la región -Perú, puntualmente- sobre el interés de la participación de Argentina, a efectos de coordinar acciones conjuntas dentro del Comité de Coordinación de los Países No Alineados para contrarrestar "la política del gobierno de La Habana en asuntos de interés latinoamericanos". ${ }^{25}$

Cuba, sobre acuerdos comerciales y financieros, 24 de mayo de 1979. Cable secreto de la Embajada de Argentina en La Habana a la cancillería, núm. 214/215. Amrec, Argentina.

${ }^{23}$ De Misión Permanente de la República ante N.U., responde consulta respecto de participación en Comité de Coordinación del Movimiento de Países No Alineados y posición del grupo moderado frente a reunión en La Habana. Referencia a contactos con Perú, 24 de enero de 1979. Cable secreto de la Misión Permanente ante Naciones Unidas de Argentina en Nueva York a la cancillería, núm. 143. Amrec, Argentina.

${ }^{24}$ De Misión Permanente de la República ante N.U., responde consulta respecto de participación en Comité de Coordinación del Movimiento de Países No Alineados y posición del grupo moderado frente a reunión en La Habana. Referencia a contactos con Perú, 24 de enero de 1979. Cable secreto de la Misión Permanente ante Naciones Unidas de Argentina en Nueva York a la cancillería, núm. 143. Amrec, Argentina.

${ }^{25}$ De Misión Permanente de la República ante N.U., responde consulta respecto de participación en Comité de Coordinación del Movimiento de Países No Alineados y posición del grupo moderado frente a reunión en La Habana. Referencia a contactos con Perú. 24 de enero de 1979. Cable secreto de la Misión Permanente ante Naciones Unidas de Argentina en Nueva York a la cancillería, núm. 143. Amrec, Argentina. 
Claramente, si bien en apariencia las relaciones entre Cuba y Argentina (1976-1983) estuvieron marcadas por una estrecha cordialidad, llegando a mostrarse en muchas ocasiones como "buenos amigos", lo cierto es que ambos gobiernos conocían sus alcances y limitaciones, sobre todo en lo que respecta a la cuestión ideológica. Precisamente, en el año 1979, el gobierno argentino no fue invitado a los festejos por el XX aniversario del triunfo de la revolución cubana, algo que generó mucho malestar en las autoridades del país austral. Un mes más tarde, después de reunirse con el director del área de América Latina de la cancillería cubana, Mario Molina Salas, embajador argentino en La Habana, comunicó a la cancillería argentina que el mismo funcionario le había expresado, a manera de comentario casual y en forma amistosa, "que altas esferas habían decidido no invitar al gobierno argentino por los festejos del XX aniversario de la Revolución en el deseo de evitarles situaciones que eventualmente podrían resultar incómodas dado el carácter de los festejos" ${ }^{26}$ Fue el propio funcionario quien, en el mismo cable, definió la mirada del gobierno de Cuba para el gobierno argentino al final de la comunicación al expresar: "Queda patentizado que Cuba no incluye al gobierno argentino entre los calificados de 'amigos"” ${ }^{27}$

\section{DE LA CRISIS DEL MARIEL A LA GUERRA DE MALVINAS}

1980 puede ser considerado uno de los años más destacados para las relaciones cubano-argentinas. Y es que Argentina, a través de su representación diplomática en La Habana, desempeñó un papel importante ante la crisis migratoria que vivió ese año el país caribeño. Desde 1959 hasta la actualidad, la cuestión migratoria ha sido un tema escabroso para las autoridades cubanas, además de un elemento de presión usado por el gobierno estadunidense para desestabilizar el proceso revolucionario cubano. En tal sentido, en 1980, un grupo de cubanos irrumpieron violentamente en las embajadas de Venezuela y Perú, situación que fue manipulada y azuzada por Estados Unidos, quien

${ }^{26}$ Conferencia Cumbre no alineados, 6 de febrero de 1979. Cable secreto de la Embajada de Argentina en La Habana a la cancillería, núm. 54/55. Amrec, Argentina.

${ }_{27}$ Conferencia Cumbre no alineados, 6 de febrero de 1979. Cable secreto de la Embajada de Argentina en La Habana a la cancillería, núm. 54/55. AMrec, Argentina. 
internacionalizó el conflicto, tomando posición explícita en favor de quienes habían violado la inmunidad de las sedes diplomáticas. Así, en la medida que la situación fue subiendo de nivel, Cuba y Estados Unidos tomaron medidas en cuanto a la población que quería migrar -el primero permitiendo las salidas por vía marítima, el otro intentando detener la entrada-, proceso que desencadenó en uno de los éxodos de cubanos más grande y violento de la historia de la isla antes de $1994,{ }^{28}$ y que internacionalmente es conocido como los “sucesos del Mariel” (Martín y Pérez, 1998, pp. 40-58).

Antes de la salida de migrantes por el puerto de Mariel, gran cantidad de cubanos permanecieron asilados en la embajada de Perú en La Habana, convirtiéndose la concentración -había hombres y mujeres de todas las edades, niños pequeños, incluso lactantes-, no sólo en un problema migratorio-diplomático, sino en una cuestión humanitaria. Precisamente, ante dicha situación, Argentina, a través de las sedes diplomáticas en Lima y en La Habana, siguieron muy de cerca el desarrollo de los acontecimientos, y rápidamente expresaron su voluntad de fungir como interlocutor en la búsqueda de posibles soluciones entre Cuba y Estados Unidos.

Así, a los pocos días de la primera incursión de cubanos en la sede diplomática peruana, la embajada argentina en Lima comunicó al Ministerio de Relaciones Exteriores de Argentina que la situación cubana merecía puntual atención. ${ }^{29}$ De igual forma lo hizo su par en La Habana quien, como muestran los cables enviados a Buenos Aires, dio cuenta de la importancia de la situación desde casi un año antes. Además de orientar a la cancillería "de abstenerse por el momento de formular ofrecimiento hasta tanto cambie el clima reinante en las autoridades del partido y principalmente en el propio Castro", ${ }^{30}$ hizo referencia a la lentitud de Estados Unidos en el otorgamiento de permisos de radicación a los cubanos como una de las causas de la presión

${ }^{28}$ El 5 de agosto de 1994 cientos de habaneros se congregaron cerca del Castillo de la Punta, en La Habana, comenzando a manifestarse, lanzando pedradas contra las vidrieras y a gritos de ¡Abajo Fidel, Abajo el comunismo! Este episodio, rápidamente reprimido por la policía y el ejército, la tensión persistente en los días posteriores, dieron lugar al famoso "Éxodo de los Balseros" de agosto de ese año, el tercero desde la Isla antes del de Camarioca 1965 y Mariel en 1980 (Aja Díaz et al., 2017; Cobas Cobiella, 2017; Martín y Pérez,1998).

${ }^{29}$ Informa sobre gestiones realizadas en relación con la situación de Cuba, 22 de abril de 1980. Cable secreto de la Embajada de Argentina en Lima a la cancillería, núm. 447. AmREC, Argentina.

30 Recepción ex detenidos cubanos, 27 de enero de 1979. Cable secreto de la Embajada de Argentina en La Habana a la cancillería, núm. 38/39. AMREC, Argentina. 
política que vivía la isla, procedimiento que estaba limitando cada vez más la migración de Cuba hacia ese país, ya que Estados Unidos estaba aceptando, exclusivamente, a los presos indultados y a los exdetenidos cubanos. ${ }^{31}$

¿Qué intereses tenía Argentina en el problema migratorio cubano, si no fue de los países que se vieron afectados directamente por la crisis migratoria, ni tampoco era un destino elegido por la sociedad cubana para emigrar?, ¿qué había detrás de la intención de ser un interlocutor? Tomando como referencia la bibliografía especializada que ha abordado la posición de Argentina para con la región centroamericana en el mismo periodo, sobre todo aquella que ha arribado a la conclusión de que el gobierno militar argentino tenía como intención reemplazar a Estados Unidos en tanto "sucedáneo calificado" en el liderazgo de la lucha contra la insurgencia en el continente (Armony, 1999; Molinari, 2018; Rostica, 2015), tal pareciera que Argentina encontró en la crisis migratoria cubana la ocasión propicia para posicionarse y ofrecerse como el interlocutor idóneo en la resolución de conflictos que, claramente, respondían a la confrontación de la guerra fría.

Asimismo, ante la situación migratoria compleja, en la cual la comunidad internacional siguió de cerca el tema de la represión y las violaciones de los derechos humanos por parte del gobierno de Cuba sobre la población que intentaba migrar, sobre todo para con los que permanecieron hacinados en la sede diplomática peruana, la crisis se convirtió en la oportunidad de lujo para que el gobierno argentino se mostrara como un "moderador y defensor de los derechos humanos" a nivel regional, cuando hacía pocos meses -apenas cuatro- se había hecho público el informe de la $\mathrm{CIDH}$, situación que tenía muy preocupadas a las autoridades militares.

Y es que, a partir de la evaluación hecha por la CIDH, la cancillería argentina ordenó debilitar la formación de opinión negativa que se pudiera formar en contra de Argentina a partir de los datos reflejados en el informe. Así, durante el mes de abril de 1979 -al menos en esa fecha de acuerdo con la documentación que existe-, envió un documento a casi todas sus representaciones diplomáticas en el exterior, en particular en la región latinoamericana, con observaciones oficiales acerca de la situación de los derechos humanos en Argentina. Este documento, el cual iba acompañado de una carta firmada personalmente por el canciller, exhortaba a neutralizar, mediante contactos

31 Recepción exdetenidos cubanos, 27 de enero de 1979. Cable secreto de la Embajada de Argentina en La Habana a la cancillería, núm. 38/39. Amrec, Argentina. 
con las autoridades de los respectivos países, funcionarios allegados, etc., toda imagen negativa que se pudiera formar respecto a Argentina, y así contrarrestar el posible impacto perjudicial a los vínculos políticos y económicos con los países de la región. ${ }^{32}$

De tal importancia fue el tema de los asilados cubanos para la cancillería que, el 23 de abril de 1980, el propio ministro de Relaciones Exteriores de Argentina, Carlos Washington Pastor resolvió, mediante la firma de la Resolución núm. 536, aprobar el viaje a la ciudad de Miami, Estados Unidos, del capitán de Navío Jorge Emiliano Portugal, director general de Control de Gestión, con el objetivo de coordinar y resolver el posible traslado de los cubanos que se encontraban en calidad de asilados en la sede diplomática peruana en La Habana. ${ }^{33}$ Meses más tarde, cuando todavía la situación no se había resuelto, el propio embajador argentino en Estados Unidos transmitió a Buenos Aires una comunicación donde ratificó la importancia y el impacto que había tenido en las autoridades estadunidenses, particularmente en el Departamento de Estado, la gestión de Emiliano Portugal con vistas a resolver el tema de los refugiados cubanos. ${ }^{34}$ Puntualmente, el funcionario hizo referencia a una conversación que había tenido con William Bowdler, en ese entonces subsecretario de Estado para Asuntos del Hemisferio Occidental, quien le había expresado que la actitud argentina era una clara demostración del espíritu solidario que animaba al gobierno argentino en la búsqueda de la solución a dicho problema, además del interés por conocer la evaluación de los resultados de la visita del comodoro Cavandoli a Guatemala y a Honduras. ${ }^{35}$

${ }^{32}$ Responde la Citel núm. 79 del Ministerio de Relaciones Exteriores y Culto informando sobre una entrevista mantenida con el vicecanciller local en relación con las observaciones argentinas al informe de la CIDH. 30 de abril de 1980. Cable secreto de la Embajada de Argentina en San José, Costa Rica, a la cancillería, núm. 313. Amrec, Argentina.

33 Autorización de desplazamiento a Miami, Estados Unidos de América, de funcionario para coordinar el posible traslado de asilados cubanos que se encuentran en la Embajada de Perú en Cuba, 23 de abril de1980. Resolución núm. 536. Reservado. AmRec, Argentina.

${ }^{34}$ Informa sobre reunión mantenida con el secretario asistente norteamericano W. Bowdler en la que se trataron: desapariciones en Rosario, refugiados cubanos, visita de comodoro Cavandoli a Guatemala y Honduras y visita de Bowdler a la Argentina, 21 de mayo de 1980. Cable secreto de la Embajada de Argentina en Washington a la cancillería, núm. 1600. AMRec, Argentina.

${ }^{35}$ Informa sobre reunión mantenida con el secretario asistente estadunidense W. Bowdler en la que se trataron: desapariciones en Rosario, refugiados cubanos, visita de comodoro Cavandoli a Guatemala y Honduras y visita de Bowdler a la Argentina, 21 de mayo de 1980. 
Sin embargo, detrás de las acciones diplomáticas argentinas en Estados Unidos, las cuales tenían como objetivo mostrar la preocupación y disposición del país austral en encontrar una salida satisfactoria a la crisis migratoria cubana, también estaba la necesidad de conocer cuál era la opinión del gobierno estadunidense sobre el informe de la CIDH, pero, sobre todo, dar su versión sobre algunos hechos de desapariciones de personas que el Departamento de Estado había reclamado a Argentina. Y es que el 15 de mayo de 1980 la embajada argentina en Washington comunicó a la cancillería, a través de un cable secreto, la grave preocupación manifiesta de funcionarios de la Oficina de Asuntos Interamericanos del Departamento de Estado acerca de una notificación que habían recibido sobre la desaparición de nueve personas en la ciudad de Rosario, quienes estaban vinculadas al Partido Socialista de los Trabajadores. Según se describía en el cable, seis de los nueve habrían desaparecido el día 7 de mayo, mientras que los tres restantes, lo hicieron el día 11. Precisamente, William Bowdler -argentino de nacimiento- le comunicó al representante diplomático en su encuentro que tenía la "viva satisfacción ante el hecho de haber desmentido la versión de la desaparición en Rosario". 36

Por último, otro de los momentos transcendentales en las relaciones cubano-argentinas fue durante la guerra de Malvinas. Cuando en 1982 se inició la confrontación armada, el gobierno cubano desempeñó un papel activo en defensa de la causa argentina. Al ostentar Cuba la presidencia del MNOAL, organizó una conferencia especial de cancilleres del grupo con el fin de que la República Argentina pudiera explicar, ante otros países y el mundo, la justeza de su demanda soberana. A pesar de haber expresado, mediante un comunicado conjunto el 26 de abril de 1982, el rechazo al accionar imperialista del Reino Unido, desde La Habana, en junio de 1982, el MNOAL aprobó una declaración final en la que expresó su respaldo a los derechos de la República Argentina a que se le restituyan las islas Malvinas, condenaron las acciones militares británicas, y lamentaron las pérdidas de vidas como resultado del conflicto armado, entre otras cuestiones (MNOAL, 1982).

Cable secreto de la embajada de Argentina en Washington a la cancillería, núm. 1600. AMREC, Argentina.

${ }^{36}$ Informa sobre reunión mantenida con el secretario asistente estadunidense W. Bowdler en la que se trataron: desapariciones en Rosario, refugiados cubanos, visita de comodoro Cavandoli a Guatemala y Honduras y visita de Bowdler a Argentina, 21 de mayo de 1980. Cable secreto de la embajada de Argentina en Washington a la cancillería, núm. 1600. AMrEC, Argentina. 
Fue en esta ocasión que, esta vez como presidente de Cuba, Fidel Castro se reunió con el canciller argentino Nicanor Costa Méndez en varias ocasiones y le reiteró, de manera enfática y a través de gestos de cordialidad hacia el pueblo y el gobierno argentino, el apoyo de Cuba al derecho de Argentina, además de que hizo eco de las denuncias hechas por el representante argentino sobre "el plan de Gran Bretaña, Sudáfrica y Estados Unidos para instalar una base militar en Malvinas". ${ }^{37}$ Por su parte, el enviado de Galtieri aprovechó la ocasión y, a través de un encendido discurso, se mostró cada vez más cercano a los No Alineados y a Cuba. Pragmáticamente, con el mismo carácter que habían tenido las relaciones entre ambos países desde 1976, y mostrándose como los amigos que en realidad no eran, Costa Méndez ensalzó a Cuba como un protagonista decisivo de la política latinoamericana del periodo, además de comparar la lucha por Malvinas con las luchas que habían llevado a cabo países referentes del Tercer Mundo. Al respecto expresó:

Con luchas similares a la nuestra, a la que hoy libramos por las Malvinas, lograron su independencia la gran mayoría de los países que hoy forman parte de este movimiento. Esa fue también la forma en que la República Argentina y los países americanos lograron su independencia a través de una gesta emancipadora, heroica. No puedo tampoco dejar de recordar que naciones como Argelia, como India, como Cuba, como Vietnam y tantas otras libraron largas luchas por la liberación y por sus plenos derechos a la vida independiente (Costa Méndez, 1982).

\section{CONSIDERACIONES FINALES}

A partir del análisis anteriormente expuesto, se puede afirmar que el gobierno revolucionario cubano mantuvo estrechas relaciones con el gobierno de facto argentino entre 1976 y 1983. La documentación diplomática revisada muestra que el golpe de Estado perpetrado en Argentina el 24 de marzo de 1976 no menoscabó las relaciones cubano-argentinas, las cuales se habían retomado con mucha intensidad desde la asunción de Héctor J. Cámpora (1973), permitiendo reconocer la arena internacional como el área de mayor acercamiento

37 Editorial, "Costa Méndez en Cuba: 'No permitiremos una base militar en Malvinas”, Clarín, Buenos Aires, 4 de junio de 1982, p. 1. 
y apoyos entre ambos gobiernos. Hechos como la reunión del Movimiento de Países No Alineados (La Habana, 1979), la crisis migratoria del Mariel (Cuba), o el respaldo político dado por Cuba a Argentina durante la guerra de Malvinas, demuestran que ambos países, aun cuando comulgaron ideologías contrapuestas, mantuvieron relaciones cordiales a partir del pragmatismo que desarrollaron en el ámbito de las relaciones exteriores.

En el caso de Cuba, el análisis de las relaciones con el gobierno de facto argentino permite refrendar que la política exterior cubana, a partir de 1970, estuvo signada por un alto grado de practicidad, lo que coadyuvó a priorizar los vínculos económicos por encima de las cuestiones ideológicas, como fue el caso de Argentina. El estudio aquí planteado permite entender cómo Cuba estableció lazos diplomáticos y económicos con países que tenían gobiernos ideológicamente opuestos, además de que creó y desplegó un variado aparato oficial dedicado a la formulación e implementación de la política exterior, en el que participaron altos oficiales del gobierno y del partido, los ministerios de relaciones exteriores y de comercio exterior, comisiones internacionales, etcétera.

Por su parte, para el gobierno de facto argentino, las fuentes analizadas también permiten extraer la importancia de las buenas relaciones con Cuba, sobre todo porque les permitió mejorar su imagen internacional en momentos cruciales, como fue durante el periodo 1978-1979. A pesar de los posicionamientos anticomunistas de las diferentes Juntas Militares argentinas que gobernaron al país, se demuestra que la cordialidad que existió para con el gobierno cubano y su líder, Fidel Castro -referente del Tercer Mundo y de la izquierda mundial- se convirtió en uno de los puntos de consenso que se dieron al interior de las respectivas Juntas Militares, reconociendo a Cuba como el "amigo necesario", lo que facilitó una reconfiguración constante de la imagen del sistema político argentino desde un aparente "consenso", pero con las Fuerzas Armadas en el poder.

Por último, es importante destacar que el estudio exploratorio que se ha hecho desacomoda los lugares comunes desde donde se han abordado los estudios latinoamericanos sobre la guerra fría. Y es que los vínculos políticos y económicos desarrollados entre el gobierno cubano y el argentino entre 1976 y 1883 , sin lugar a dudas, interpela aquellas perspectivas que a nivel mundial han establecido un corpus interpretativo e identitario sobre la guerra fría en América Latina, basado únicamente en el encolumnamiento de los países/ gobiernos en el clásico debate ideológico de "capitalismo-comunismo" o "confrontación Este-Oeste”. Además, un enfoque de estas características aporta 
un análisis diferente acerca de un proceso histórico puntual que marcó, y sigue marcando, el desarrollo ideológico latinoamericano, y al mismo tiempo que se convierte en punto de partida para futuras investigaciones.

\section{LISTA DE REFERENCIAS}

Aja Díaz, A., Rodríguez Soriano, M. O., Orosa Busútil, R. y Albizu-Campos Espiñeira, J. C. (2017). La migración internacional de cubanos. Escenarios actuales. Novedades en Población, 13(26), 40-57. Recuperado de http://scielo.sld.cu/scielo. php?script=sci_arttext\&pid=S1817-40782017000200004\&lng=es\&tlng=es

Alzugaray Treto, C. (diciembre, 2009). La revolución cubana y su influencia en las izquierdas latinoamericanas y caribeñas, Simposio sobre el 50 Aniversario de la Revolución Cubana. Instituto de Estudios Latinoamericanos de Kyoto-Universidad de Estudios Extranjeros de Kyoto, Japón.

Argento, A. (2013). La guardería montonera. La vida en Cuba de los hijos de la Contraofensiva. Buenos Aires: Marea Editorial.

Armony, A. (1999). La Argentina, los Estados Unidos y la cruzada anticomunista en América Central, 1977-1984. Buenos Aires: Universidad Nacional de Quilmes.

Bethell, L. y Roxborough, I. (2005). The impact of the cold war on Latin America. En M. P. Leffler y D. S. Painter, Origins of the cold war. An international history. Nueva York/Londres: Taylor \& Francis e-Library.

Buch, L. M. y Suárez, R. (2009). Gobierno revolucionario cubano: Primeros pasos. La Habana: Editorial de Ciencias Sociales.

Canelo, P. V. (2001). La legitimación del Proceso de Reorganización Nacional y la construcción de la amenaza en el discurso militar. Argentina, 1976-1981. Sociohistórica, 9-10. Recuperado de

https://www.sociohistorica.fahce.unlp.edu.ar/article/view/SHn9-10a04

Castañeda, J. (1995). La utopía desarmada. Barcelona: Editorial Ariel.

Castro, F. (1985). Sobre la deuda impagable de América Latina, sus consecuencias imprevisibles y otros temas de interés político e histórico. La Habana: Editora Política.

Cobas Cobiella, M. E. (2017). La cuestión migratoria cubana. Algunas consideraciones. Barataria. Revista Castellano-Manchega de Ciencias Sociales, 23, 159-173. Recuperado de https://www.redalyc.org/journal/3221/322153763011/html/

(СIDH) [Comisión Interamericana de Derechos Humanos] (14 de diciembre, 1979). Informe sobre la situación de los derechos humanos en Argentina. Recuperado de http://desaparecidos.org/nuncamas/web/document/internac/cidh79/index.htm 
Costa Méndez, N. (3 de junio, 1982). Discurso del canciller argentino Nicanor Costa Méndez en la reunión de Países No Alineados, La Habana. Recuperado de https://www.iri.edu.ar/publicaciones_iri/IRI\%20COMPLETO\%20-\%20Publicaciones-V05/Publicaciones/I2/I2-2Z.htm

Domínguez, J. (1997). U. S.-Cuban relations: From the cold war to the colder war. Journal of Interamerican Studies and World Affairs, 39(3), 49-75.

Frediani, R. (6 de mayo, 2019). La deuda de Cuba con Argentina: US\$4.805 M. El Economista. Recuperado de https://eleconomista.com.ar/2019-05-la-deuda-de-cuba-con-argentina-us-4-805-m/

Kruijt, D. (2019). Cuba y sus lazos con América Latina y el Caribe, 1959-presente. Revista Uruguaya de Ciencia Política, 28(1), 279-301. Recuperado de http://rucp. cienciassociales.edu.uy/index.php/rucp/article/view/434

Liberman, T. (2017). La influencia de la revolución cubana en la izquierda latinoamericana: reflexiones para la construcción de nuevos caminos en el siglo xxI. En C. Masón (ed.), Las izquierdas latinoamericanas: multiplicidad y experiencias durante el siglo xx. Santiago: Ariadna Ediciones.

Lvovich, D. (2010). Actitudes sociales durante la dictadura militar argentina: las organizaciones sociales y el diálogo político de 1980. En E. Bohoslavsky et al., Problemas de historia reciente del Cono Sur (vol. 2). Buenos Aires: Prometeo Libros.

Marchesi, A. (2017). Escribiendo la guerra fría latinoamericana: entre el sur "local" y el norte "global". Estudos Históricos, 30(60), 187-202. DoI: https://doi.org/10.1590/ S2178-14942017000100010

Martín, C. y Pérez, G. (1998). Familia, emigración y vida cotidiana en Cuba. La Habana: Editora Política.

Méndez Méndez, J. L. (2006). Bajo las alas del cóndor. La Habana: Editorial San Luis.

Méndez Méndez, J. L. (12 de agosto, 2011). La Operación corU: la saga terrorista 35 años después. Cubadebate. Recuperado de http://www.cubadebate.cu/opinion/2011/08/12/la-operacion-coru-la-saga-terrorista-35-anos-despues-ii/\#. XSKvNuhKjIV

Molinari, L. (2018). La dictadura argentina frente al estallido de la guerra civil salvadoreña (1977-1982): proyección continental y "experiencias compartidas". Diálogos. Revista Electrónica de Historia, 19(2), 232-268. DoI: https://doi.org/10.15517/dre. v19i2.31173

(MNOAL) [Movimiento de Países No Alineados] (1982). Documentos de la reunión ministerial del Buró de Coordinación de los Países No Alineados. La Habana, 31 de mayo-5 de junio de 1982. Comunicado final. Recuperado de: https://www.iri.edu.ar/publica- 
ciones_iri/IRI\%20COMPLETO\%20-\%20Publicaciones-V05/Publicaciones/I2/ I2-2Z.htm

Pettinà, V. (2018). Historia mínima de la guerra fría en América Latina. México: El Colegio de México.

Prieto Rozos, A. (2017). Etapas en las concepciones y retos de la izquierda latinoamericana. En C. Masón (ed.), Las izquierdas latinoamericanas: multiplicidad y experiencias durante el siglo xx. Santiago: Ariadna Ediciones.

Prieto-Solís Cubas, A. (director), Pérez Cadenas, W. A. (productor) (2016). Más allá del dolor (mediometraje). Cuba: Estudios Mundo Latino.

Ratliff, W. (1976). Castroism and communism in Latin America, 1959-1976: The varieties of marxist-leninist experience. Washington: American Enterprise Institute for Public Policy Research.

Rodríguez, C. R. (1983). Veinte años de Cuba revolucionaria. Treinta años del came. En Letra con Filo (t. II). La Habana: Editorial Ciencias Sociales.

Rostica, J. C. (2015). Las dictaduras militares en Guatemala (1982-1985) y Argentina (1976-1983) en la lucha contra la subversión. Latinoamérica. Revista de Estudios Latinoamericanos, 60, 13-52. Recuperado de http://latinoamerica.unam.mx/index. php/latino/article/view/51683/46133

Silva, A. (2005). Nacimiento y desarrollo del socialismo. En Cuba y su historia. Ciudad de La Habana: Editorial Félix Varela.

Suárez Salazar, L. (1986). La política de la revolución cubana hacia América Latina y el Caribe: notas para una periodización. Cuadernos de Nuestra América, 3(6).

Suárez Salazar, L. (1997). Cuba: ¿aislamiento o reinserción en un mundo cambiado? La Habana: Editorial Ciencias Sociales.

\section{OTRAS FUENTES}

\section{Archivo}

AMrec Archivo del Ministerio de Relaciones Exteriores y Culto, Argentina.

\section{Hemerografía}

Granma, 1976.

Clarín, 1982. 